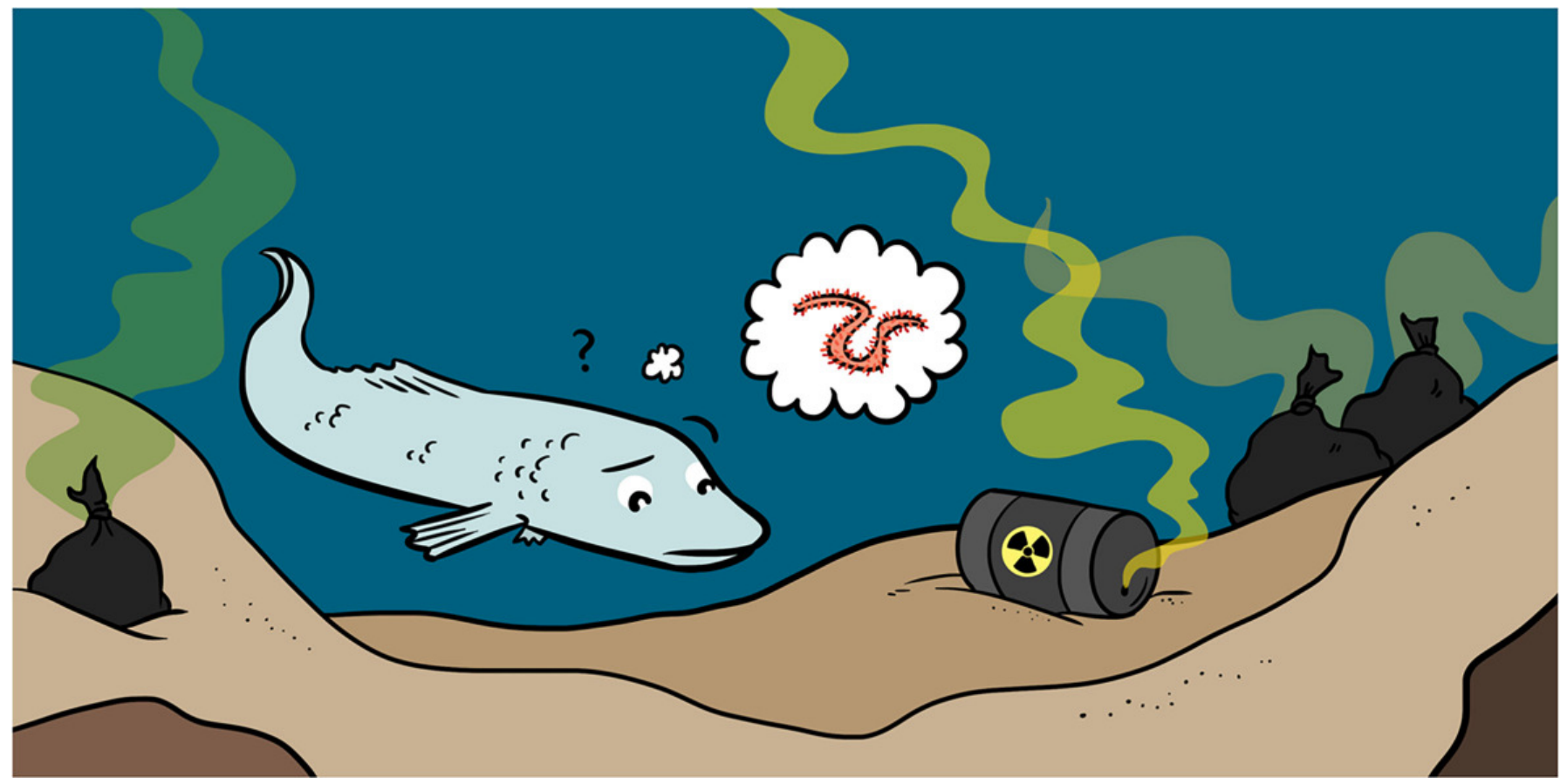

\title{
WHY ARE AQUATIC WORMS DISAPPEARING FROM MUMBAI BAY IN INDIA?
}

\section{Gobardhan Sahoo *}

The Leon H. Charney School of Marine Sciences, University of Haifa, Haifa, Israel

YOUNG REVIEWERS:

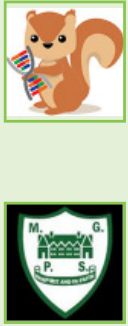

ARIA

AGE: 9

MANOR

GARDENS

PRIMARY

SCHOOL

AGES: $12-13$
Have you ever played in the mud and seen some worms in it? Do you know that there are also worms in the sand or mud of rivers and oceans? Aquatic worms keep rivers and oceans healthy. Like the worms on land, aquatic worms eat the material from dead plants and even other animals. But aquatic worms are also food for other species, like some kinds of fish. As you know, fish are very important: humans and thousands of other animals need to eat fish to survive. However, aquatic worms are disappearing in some regions of the world. I will tell you why this is happening and what I have witnessed in the Mumbai Bay in India.

\section{WHY ARE ALL SPECIES IMPORTANT?}

The oceans cover around $71 \%$ of the Earth's surface. The diversity of life in the ocean is as big as the oceans themselves. There are so many species that no one knows the names of them all, and many ocean species are yet to be discovered. There are tiny creatures that you can only see with a microscope, and others that are gigantic, like the blue whale, which can be $30 \mathrm{~m}$ long! It is the biggest animal on Earth! 


\section{ECOSYSTEM}

A group of different life forms living together and interacting with each other and with their environment.

\section{BIODIVERSITY}

Different forms of life in an ecosystem, ranging from microorganisms to large animals.

\section{FOOD CHAIN}

The order in which organisms depend on each other for food in an ecosystem.
All species are different; they vary in shape, size, color, and many other characteristics. But all species are important-even the microscopic creatures are as important as the gigantic blue whale. The health of the ocean, or of the river near where you live, depends on the presence of many different species [1]. In fact, this is true for any ecosystem on Earth, from the oceans to the tropical forests. The higher the number of species, or biodiversity, the healthier an ecosystem is [1]. However, when a river or ocean becomes polluted, many species disappear. This is not only bad for the people who cannot swim in the water or eat the fish, but it is also bad for all the species that live in that ecosystem or that go there to find their food [1].

\section{AQUATIC WORMS}

Did you know that there are worms living in the sand and mud of rivers and the ocean? Some of these aquatic worms can be 5 or $10 \mathrm{~cm}$ long, much like worms on land. But other types of aquatic worms are very small: some only measure $0.5 \mathrm{~mm}$, which is half the size of the tip of your pencil or pen. However, these tiny aquatic worms make up the majority of the animals that live in the sand or mud. Can you imagine having 5,000 small worms under your feet when you are at the beach getting your feet wet before a swim? Now you can tell everyone that beaches may look like deserts, but life thrives under everyone's feet, literally.

I mentioned that all species are important to create healthy ecosystems [1]. So, why are aquatic worms so important for oceans or rivers? Scientists found that aquatic worms, like worms on land, are part of a food chain. For example, crabs eat the worms (particularly bristle worms), and both crabs and worms are consumed by fish, such as the Northern whiting (Figure 1). This fish plays an important role in the fish industry of Mumbai. Thus, a healthier ocean with lots of worms provides fish for us to eat. Various types of worms found in marine sediments are shown in Figure 2. Without the worms, worm-eating fish might change their diets and begin competing with other species for food, which would bring changes into the ecosystem in an unhealthy way.

\section{WHY ARE AQUATIC WORMS DISAPEARING?}

Biodiversity is decreasing in many coastal areas around the world. This means that the numbers of species or individuals of a species that live in these areas is getting smaller. If you live near the ocean, this might be happening near you, without anyone noticing it. In most cases, biodiversity is decreasing because of pollution. There are many kinds of pollution that impact aquatic ecosystems. Sometimes accidents involving oil tankers or oil platforms spill oil into the ocean. Aquatic worms are extremely sensitive to oil spills and are affected quite 


\section{Figure 1}

An example of a simplified food chain. Arrows point away from the organism that is eaten to the organism that eats it.

\section{POLLUTANTS}

Chemicals or solid wastes that are harmful to organisms.

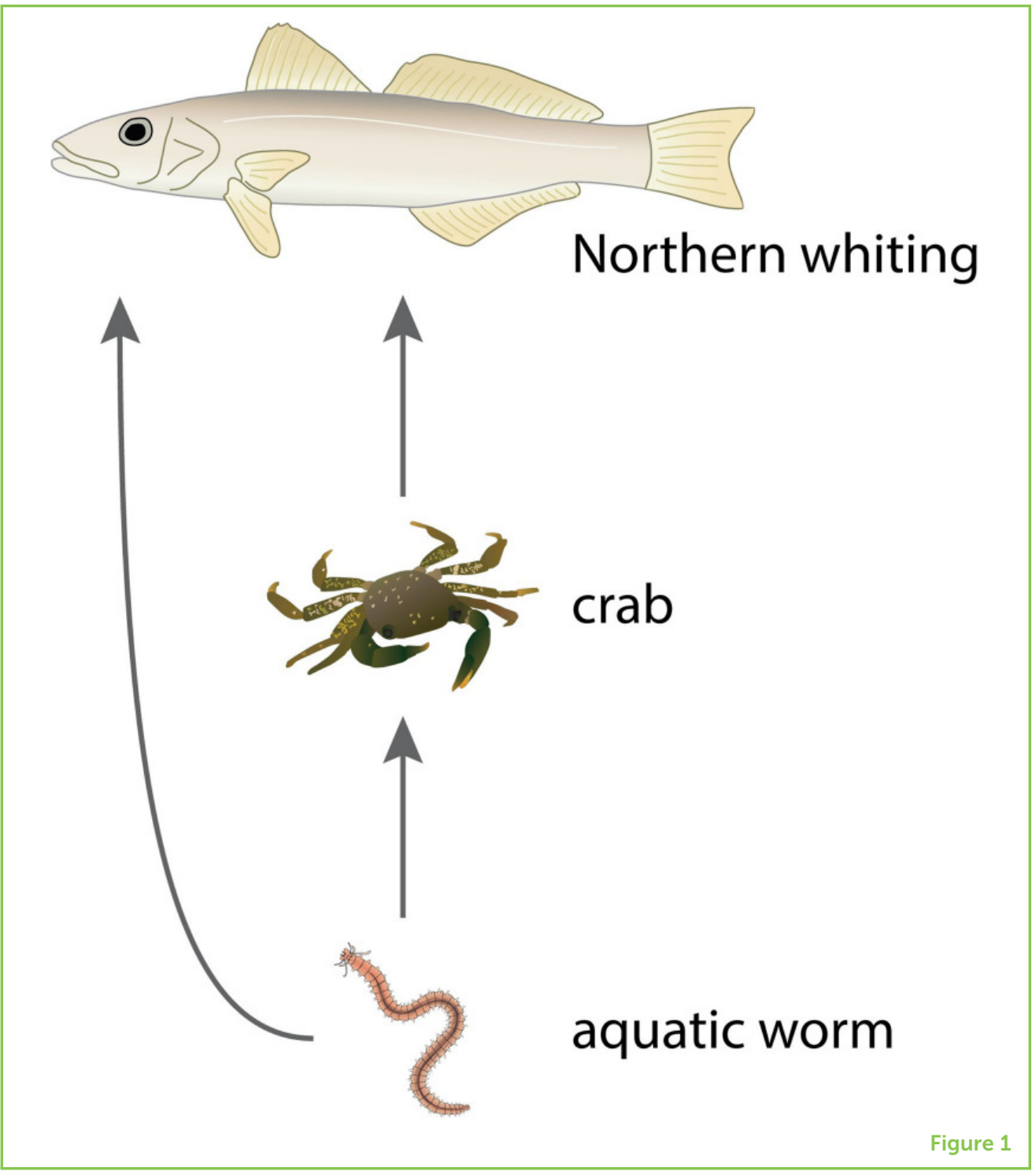

rapidly. Since these organisms cannot move swiftly, they are prone to death. Death of aquatic worms was observed after the accidental oil spills that happened off the north coast of France in 1978 [2], and off the northeast coast of Italy in 1991 [3]. A similar oil spill also happened in the central west coast of India (Mumbai Bay) in 2010, causing massive damage to marine biodiversity, including the worms living in the mud. Aquatic pollution can also come from the farms that are used grow our food. Water drained from farmlands gets into creeks and rivers, which carry the excess nutrients and pesticides into the oceans.

You are likely aware that pollutants are sometimes dumped into water from city or industrial sewers. Sadly, many cities dump their sewer water into rivers and oceans without treating it first. This is the reality in the Mumbai Bay in India, which is highly polluted [4]. Mumbai is one of the biggest cities in India and in the world. The amount of sewage that is dumped into the Mumbai Bay could fill 7,200 Olympic 
Figure 2

Diversity of worms found in marine sediments [Photo credits: Gobardhan Sahoo (roundworm); biodiversity4all.org (remainder)].
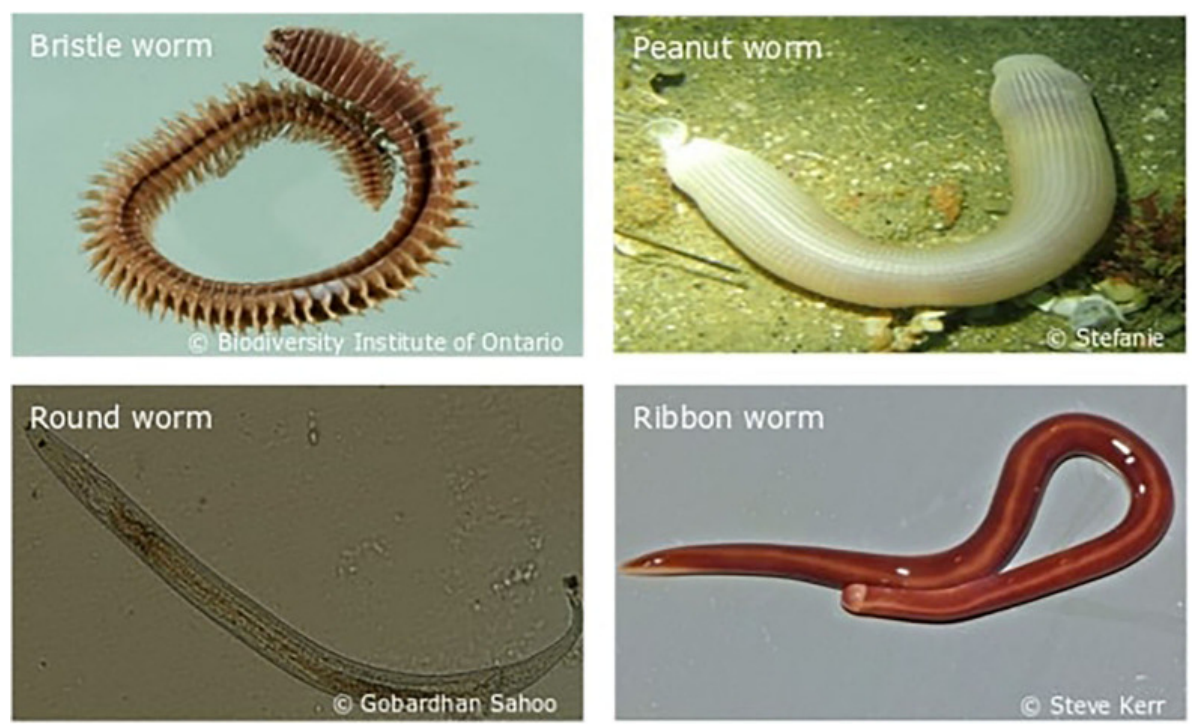

Figure 2

swimming pools each day! Can you imagine this? I cannot. Before the heavy pollution started in the Mumbai Bay, there were many thousands of aquatic worms living there. In some places you could count 10,000 worms in an area the size of a box measuring $2 \mathrm{~cm}$ by $5 \mathrm{~cm}$. Now, the number of aquatic worms has decreased to the point that, in many places, they are completely gone! This drastically affects food chains and food webs and may be one of the reasons why there has been a drastic decline in many marine fish species that are explored commercially in this area over the last few decades [5]. The disappearance of aquatic worms is happening in many other places around the globe, too.

As you can now imagine, humans are dumping a cocktail of toxic chemicals into the ocean, and many of these pollutants will impact marine plants and animals. Some pollutants immediately kill aquatic animals and plants, while other pollutants do not kill them but may cause deformities that will make their lives extremely difficult. Aquatic worms are extremely sensitive to aquatic pollution and are used as an indicator of the impact of aquatic pollution.

\section{SAY NO TO POLLUTION}

All over the planet, pollution is causing the disappearance of aquatic worms and many other species that we like so much, including fish, dolphins, crabs, and shrimp. To survive, these organisms need to have ecosystems with unpolluted water, where they can find food. I hope that you will share this story with your family, friends, and teachers. You yourself can help to protect the marine environment. If you live in India, do not dispose of any artificial colors in the water, especially during the celebration of Holi (Festival of color), as these chemicals might affect 
the worms. Maybe you and your family or friends can reach out to politicians and ask them to protect the oceans, by keeping the water clean and free of pollutants. The health of the planet, as well as the health of humans, depends on all living species, big and small, which in turn depends on clean soil, clean air, and clean water.

\section{ACKNOWLEDGMENTS}

I am thankful to the reviewers and Editor, Dr. Pedro Morais, for comments/suggestions which improved the manuscript.

\section{ORIGINAL SOURCE ARTICLE}

Sahoo, G., Ansari, Z. A., Sukumaran, S., and Gajbhiye, S. N. 2017. Defaunation of meiofauna in Mumbai bay (India)-a severely polluted area. Reg Stud Mar Sci. 16:98-108. doi: 10.1016/j.rsma.2017.08.003

\section{REFERENCES}

1. Cochrane, S. K., Andersen, J. H., Berg, T., Blanchet, H., Borja, A., Carstensen, J., et al. 2016. What is marine biodiversity? Towards common concepts and their implications for assessing biodiversity status. Front Mar Sci. 3:248. doi: $10.3389 /$ fmars.2016.00248

2. Boucher, G. 1980. Impact of amoco cadiz oil spill on intertidal and sublittoral meiofauna. Mar. Poll. Bull. 11:95-101.

3. Danovaro, R., Fabiano, M., and Vincx, M. 1995. Meiofauna response to the agip abruzzo oil spill in subtidal sediments of the Ligurian sea. Mar. Poll. Bull. 30 , 133-45. doi: 10.1016/0025-326X(94)00114-O

4. Murthy, R. C., Rao, Y. R., and Inamdar, A. B. 2001. Integrated coastal management of Mumbai metropolitan region. Ocean Coast. Manage. 44:355-69. doi: 10.1016/S0964-5691(01)00055-2

5. Deshmukh, V. D. 2013. "Responsible marine fisheries: reflections from Maharashtra," in ICAR Funded Short Course on "ICT -Oriented Strategic Extension for Responsible Fisheries Management, 05-25 November (Kochi).

SUBMITTED: 13 November 2019; ACCEPTED: 18 October 2021;

PUBLISHED ONLINE: 11 November 2021.

EDITED BY: Pedro Morais, University of Algarve, Portugal

CITATION: Sahoo G (2021) Why Are Aquatic Worms Disappearing From Mumbai Bay in India? Front. Young Minds 9:511988. doi: 10.3389/frym.2021.511988

CONFLICT OF INTEREST: The author declares that the research was conducted in the absence of any commercial or financial relationships that could be construed as a potential conflict of interest. 

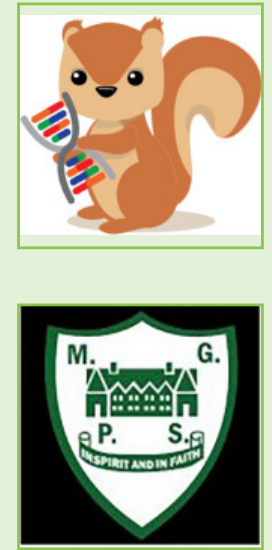

COPYRIGHT () 2021 Sahoo. This is an open-access article distributed under the terms of the Creative Commons Attribution License (CC BY). The use, distribution or reproduction in other forums is permitted, provided the original author(s) and the copyright owner(s) are credited and that the original publication in this journal is cited, in accordance with accepted academic practice. No use, distribution or reproduction is permitted which does not comply with these terms.

\section{YOUNG REVIEWERS}

\section{ARIA, AGE: 9}

Aria loves playing with her two guinea pigs and feeding birds and squirrels in her backyard. She gave each squirrel a unique name and lots of peanuts. Aria is always curious about science and she has a lot of questions about nature, animals, and the universe. She also likes singing and drawing in her spare time.

\section{MANOR GARDENS PRIMARY SCHOOL, AGES: 12-13}

We are a small, progressive, problem-solving school that encourages independent thinking. We challenge ourselves and our teachers and have lots of fun during the school day.

\section{AUTHOR}

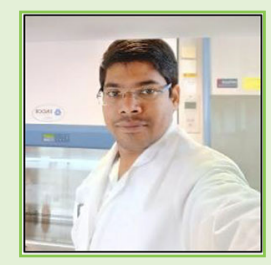

\section{GOBARDHAN SAHOO}

I received my doctorate in October 2018 from the Academy of Scientific and Innovative Research (AcSIR), India. Now, I am working as a researcher at the University of Haifa in Israel. I like to study the diversity of animals living in the ocean and the roles they play there. I have a few hobbies. I like to listen to music and sing. I also enjoy reading the biographies of great scientists whose discoveries and inventions radically changed the way we understand the world. Finally, I also love to write popular articles for children, like this one, and articles for scientists. *gsahoo@campus.haifa.ac.il 